\title{
Modality-specific forgetting
}

\section{Ashleigh M. Maxcey ${ }^{1} \cdot$ Laura Janakiefski $^{1} \cdot$ Emma Megla $^{1} \cdot$ Madison Smerdell $^{1} \cdot$ Samantha Stallkamp $^{1}$}

Published online: 18 March 2019

(C) The Psychonomic Society, Inc. 2019

\begin{abstract}
A large body of literature agrees that accessing a target memory appears to trigger a difference-of-Gaussian memory activation pulse under which the target representation is activated and categorically flanking items are suppressed and forgotten. The nature of the underlying forgetting mechanism is far from settled, with support for several theories of forgetting. Here we argue the debate is partly fueled by different forgetting mechanisms underlying the forgetting of different memoranda. We capitalized on the unique aspect of the recognition-induced forgetting paradigm to test forgetting of both pictures and words in identical recognition-practice and restudy tasks. We found that memory for pictures and words followed different patterns of forgetting. Specifically, forgetting was retrieval specific for words, in that forgetting occurred only when words were recognized, and not when words were merely restudied. However, forgetting was not retrieval specific for pictures, in that forgetting occurred both when pictures were recognized as well as restudied. Further, patterns of forgetting operated along different category-level groupings for pictures and words. Words grouped along the superordinate level were susceptible to forgetting but pictures were not. The strength of this design is the ability to directly compare forgetting for different memoranda, establishing that patterns of forgetting are modality specific. These findings demonstrate that the mechanisms underlying forgetting may differ as a function of the particular memoranda, emphasizing the need for examining forgetting in long-term memory across modalities.
\end{abstract}

Keywords Visual perception $\cdot$ Memory $\cdot$ Human memory $\cdot$ Human memory and learning

\section{Introduction}

A fundamental assumption of human memory is that memory representations interact (e.g., Schlichting \& Preston, 2015). This is supported, for example, in demonstrations of interference (Kelley, Neath, \& Surprenant, 2015; Konkle, Brady, Alvarez, \& Oliva, 2010a, 2010b; Koutstaal \& Schacter, 1997; Raaijmakers \& Jakab, 2013a, 2013b; Underwood, 1957). Access-based forgetting (i.e., recognition- and retrieval-induced forgetting) shows that this interaction in memory has a very particular form in which the distance of the memory representations in psychological space determines whether they interact (Anderson, Bjork, \& Bjork, 1994; Maxcey \& Woodman, 2014). Items that are nearby one another in category space will inhibit one another, creating inhibitory surrounds in memory. In Fig. 1 we illustrate this pattern of

Ashleigh M. Maxcey

ammaxcey@gmail.com

1 Department of Psychology, The Ohio State University, 1835 Neil Ave., Columbus, OH 43210, USA memory strength by showing that accessing a targeted memory triggers a difference-of-Gaussian memory activation pulse in which the target memory is activated and flanking memories are suppressed and forgotten.

Theoretical frameworks of forgetting have described such inhibitory surrounds in memory as being due to different underlying mechanisms. Popular forgetting accounts have proposed that forgetting is due to mechanisms such as moderate activation (Detre, Natarajan, Gershman, \& Norman, 2013; Kim, Lewis-Peacock, Norman, \& Turk-Browne, 2014; Lewis-Peacock \& Norman, 2014; Norman, Newman, \& Detre, 2007), competition (Raaijmakers \& Jakab, 2013a, 2013b), inhibition (Anderson, 2003; Murayama, Miyatsu, Buchli, \& Storm, 2014; Storm \& Levy, 2012), and context (Jonker, Seli, \& MacLeod, 2013). Why is the underlying mechanism of forgetting unresolved?

Here we propose that different mechanisms may underlie forgetting as a function of memoranda and task. Take, for example, the popular forgetting phenomenon retrieval-induced forgetting. Retrieval-induced forgetting was originally demonstrated with words (Anderson et al., 1994), but has been shown to generalize to a variety of materials such as visual-spatial objects (Ciranni \& Shimamura, 1999), eyewitness memories 


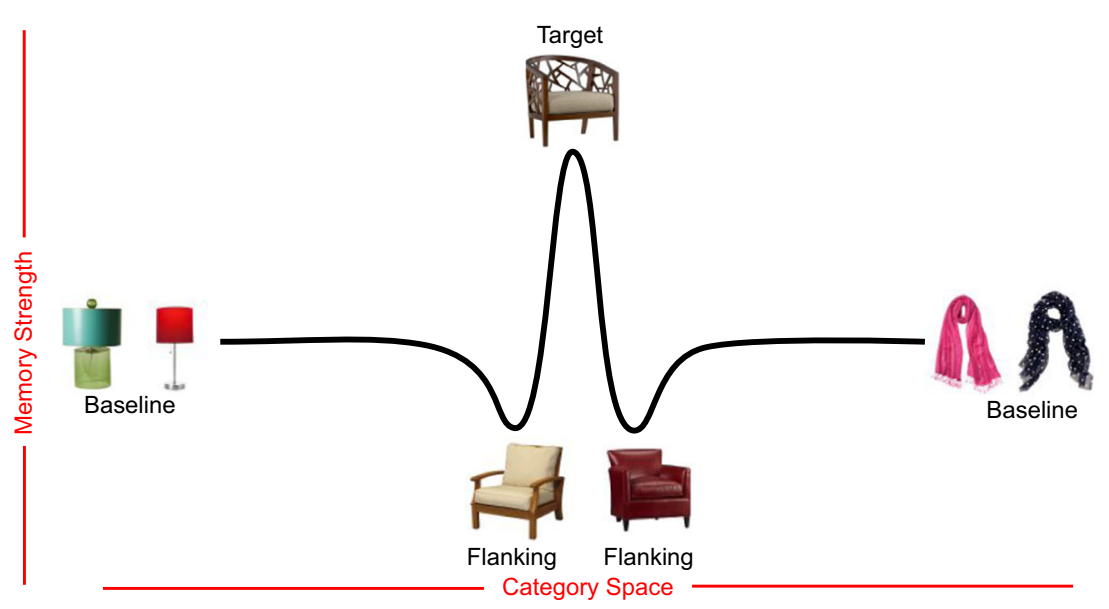

Fig. 1 Difference-of-Gaussian activation pulse triggered by accessing an object held in long-term memory

(Shaw, Bjork, \& Handal, 1995), motor memory (Tempel, Aslan, \& Frings, 2016), and location information (Gómez-Ariza, Fernandez, \& Bajo, 2012). Given that the above-named theories of forgetting attempt to account for retrieval-induced forgetting, the many stimulus types susceptible to this forgetting effect may be a liability in elucidating the underlying mechanism. This is particularly likely because we know that memory for some types of stimulus material is better than others, as in the picture superiority effect, by which memory for pictures is better than memory for words (Durso \& O'Sullivan, 1983; Gehring, Toglia, \& Kimble, 1976; Hockley, 2008; Juola, Taylor, \& Young, 1974; Madigan, 1974; Nelson, Reed, \& McEvoy, 1977; Nelson, Reed, \& Walling, 1976; Paivio \& Csapo, 1973; Paivio, Rogers, \& Smythe, 1968; Snodgrass \& Burns, 1978; Snodgrass, Volvovitz, \& Walfish, 1972; Snodgrass, Wasser, Finkelstein, $\&$ Goldberg, 1974). This distinction in the nature of the memoranda naturally suggests that the underlying mechanism responsible for the forgetting of one type of material may be fundamentally different to another type of material.

Here we employed the recognition-induced forgetting paradigm (Maxcey, 2016; Maxcey \& Bostic, 2015; Maxcey, Bostic, \& Maldonado, 2016; Maxcey, Glenn, \& Stansberry, 2017; Maxcey \& Woodman, 2014; Rugo, Tamler, Woodman, \& Maxcey, 2017) to directly test whether the nature of the memoranda determines the forgetting mechanism. This paradigm is divided into three phases (Fig. 2) intervened by 5-min delay intervals. The experiment begins in the study phase during which subjects are presented with items to remember for a later memory test. In the second phase, subjects engage in an old-new recognition judgment task during which they are shown items and asked if they have ever seen that exact image earlier in the experiment. This phase is called the practice phase because subjects are engaged in practice accessing the target information in memory. Finally, in the test phase, the subjects complete an old-new recognition judgment task, an identical task to the practice phase.
The hit rates from the old-new recognition judgment task in the test phase are analyzed along three old object types. Target ${ }^{1}$ items were studied in the study phase, and subjects practiced recognizing them twice in the practice phase. When memory for target items was tested during the test phase by presenting the target item for an old-new recognition judgment, the target items have been seen three times earlier in the experiment. Flanking items were shown in the study phase and were not practiced in the practice phase, although other items from their category were practiced (e.g., some vases were practiced but not this particular vase). When flanking items are presented during the test phase, they have only been seen once earlier in the experiment. Baseline items belong to categories that were not presented during the practice phase. Just like flanking items, at test baseline items have only been seen once earlier in the experiment. The signature pattern of data for recognition-induced forgetting is reliably worse performance for flanking items relative to baseline items, measured in the test phase (Fig. 1).

An advantage to the present paradigm is that we can use identical experimental conditions with the sole manipulation being the nature of the memoranda. This unique advantage allows us to directly compare memory for pictures and words following a variety of tasks. To this end, we compared the forgetting of visual stimuli with verbal stimuli following a recognition practice task (Experiment 1) and a novel restudy task (Experiment 2). Previous work had not been able to assess induced forgetting effects of visual objects using retrieval tasks, like stem completion with words, as it is unclear how one would measure the accuracy of retrieving a picture (Maxcey \& Woodman, 2014). The recognition-induced forgetting paradigm was originally developed to solve this problem and examine the forgetting of pictures, hence this paradigm has not

\footnotetext{
${ }^{1}$ Relative to our previous work, we are using revised nomenclature to refer to object types in order to illustrate the difference-of-Gaussian shape of the results. Here we call practiced items target items and related items are called flanking items.
} 
Picture Recognition Practice Condition

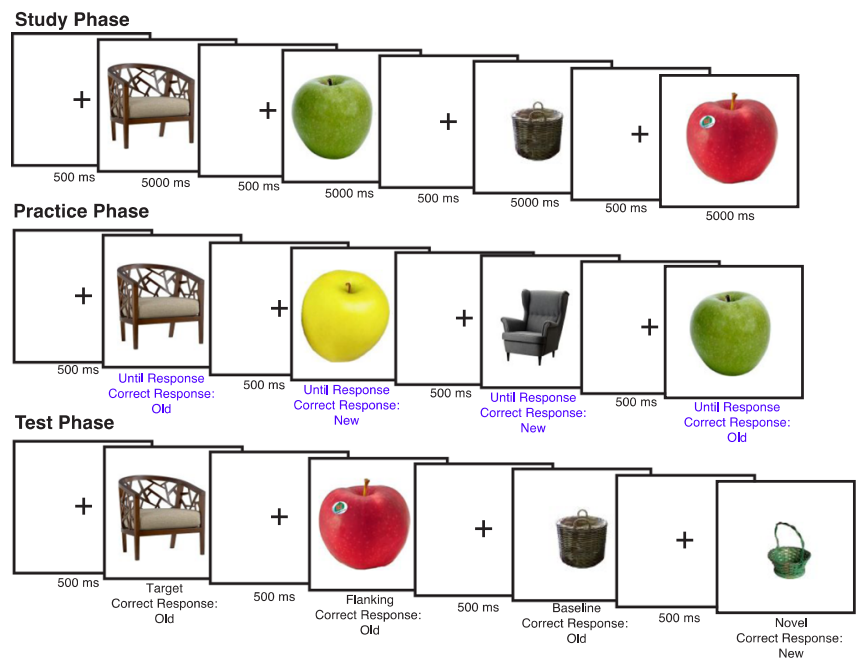

Fig. 2 The methods for the picture condition are shown on the left and methods for the word condition are shown on the right. In the study phase, subjects fixated a central fixation point for $500 \mathrm{~ms}$, followed by the presentation of the stimuli for $5,000 \mathrm{~ms}$, until all stimuli were presented. The subjects were instructed to remember each item for a later memory test. The study phase was followed by a 5-min visual distractor task. In the second phase, half of the items from half of the categories were again presented along with an equal number of novel items. The subject's task differed depending on experiment. In Experiments 1 and 3, subjects engaged in recognition practice by completing an old-new recognition judgment task in response to each

previously employed word stimuli. Comparing across tasks, such as existing recognition-induced forgetting studies of pictures and retrieval-induced forgetting studies of words, is insufficient because even within the same modality, different types of memory tests yield different results (Cunningham, Yassa, \& Egeth, 2015). In Experiment 1, we examined the forgetting of words in the recognition-induced forgetting paradigm for the first time. Experiment 1 included a picture condition. In Experiment 2, we examined the restudy of pictures for the first time. Experiment 2 included a word condition. If either the recognition practice or the restudy tasks differentially affect forgetting of visual and verbal stimuli, then different forgetting mechanisms may account for the forgetting of different memoranda. If, on the other hand, these tasks similarly impact the forgetting of visual and verbal materials, then modality-specific forgetting mechanisms need not be proposed.

\section{Experiment 1}

\section{Methods}

\section{Participants}

Subjects were The Ohio State University undergraduates who completed the experiment in exchange for course
Word Recognition Practice Condition

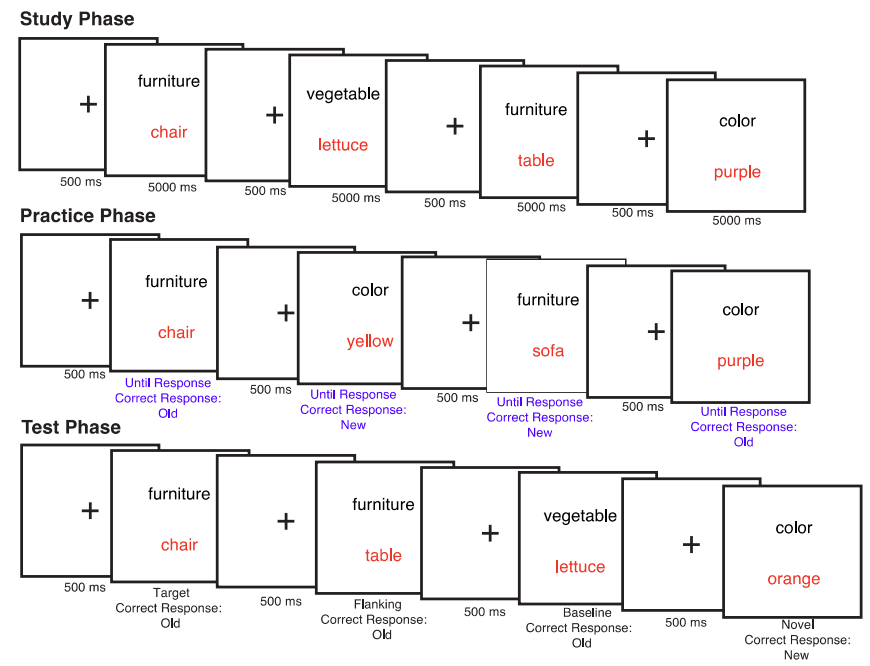

item (pictured in blue font here). Each old item was practiced on two practice trials. The practice lures were items drawn from the same categories as the practice items. In Experiment 2 subjects engaged in restudy (not pictured here). The task of the second phase replicated the study phase with subjects studying the words. The words were presented for 5,000 ms each. The second phase was followed by another 5-min visual distractor task. The test phase employed the same old-new recognition judgment task as the second phase in Experiment 1, but included 48 of the stimuli from the study phase (four from each of 12 categories) as well as an equal number of novel test lures from the same categories

credit. The participants reported normal color vision and normal or corrected-to-normal visual acuity. Informed consent was obtained prior to the beginning of the experiment, and all procedures were approved by the Institutional Review Board.

Subjects were randomly assigned to one of two experimental conditions after informed consent was obtained: picture recognition practice (44 subjects, mean age of 20.3 years, 26 female, 18 male) or word recognition practice (44 subjects, mean age of 18.8 years, 19 female, 25 male).

A pilot experiment with 33 subjects was run to determine the necessary sample size (Faul, Erdfelder, Lang, \& Buchner, 2007). In the pilot experiment, the smallest effect we measured had a $d_{z}=.76$. If we wanted to have $99 \%$ power to detect an effect equal to this with a two-tailed ttest, we would require 34 subjects per condition, ensuring adequate power with data from 44 subjects in each condition.

\section{Stimuli and apparatus}

Stimuli were presented on a white background on a flatscreened CRT monitor using E-prime software (Schneider, Eschman, \& Zuccolotto, 2012). The object categories were either all words or all pictures, depending on the experimental condition to which the subject was 
assigned. The stimulus sets, shown in Table 1 and Appendix A, consisted of 12 categories with 15 exemplars from each category. The specific practiced categories were counterbalanced across subjects. Subjects reported whether the pictures or words were old or new during the second recognition-practice phase and the final test phase using a dedicated Chronos response box. Subjects were seated approximately $80 \mathrm{~cm}$ from the monitor in a dimly lit room. Stimuli subtended approximately $4.6^{\circ}$ of visual angle.

\section{Procedure}

In the study phase, six exemplars from each of the 12 categories were presented in 72 total trials. Half of the studied categories were included in the second phase.
For the six categories included in the second phase, three old exemplars were repeated on two trials each, totaling 18 old objects presented on 36 old trials. This design required six new exemplars from each category included in the second phase, totaling 36 new, for a 50-50 old-new correct response distribution. The second phase included 72 total trials. At test, memory was tested for two old baseline items, two old target items, two old flanking items, and six novel items drawn from the same categories totaling 72 test trials. The stimuli were sequentially presented in all three phases, as shown in Fig. 2.

\section{Data analysis}

The primary dependent variable for recognition memory is hit rate across the three main object types: target,

Table 1 Stimuli from word conditions in Experiments 1 and 2

\begin{tabular}{|c|c|c|c|c|c|}
\hline Kitchen & Earth Formation & Bird & Body Part & Color & Fruit \\
\hline Fork & Volcano & Hawk & Arm & Red & Peach \\
\hline Spoon & River & Crow & Foot & Green & Grape \\
\hline Pan & Hill & Robin & Head & Orange & Strawberry \\
\hline Bowl & Canyon & Parrot & Mouth & White & Mango \\
\hline Mixer & Glacier & Dove & Stomach & Pink & Cherry \\
\hline Cup & Boulder & Falcon & Back & Brown & Nectarine \\
\hline Pot & Lake & Eagle & Nose & Purple & Pear \\
\hline Whisk & Ocean & Blue Jay & Toe & Yellow & Banana \\
\hline Spatula & Mountain & Hummingbird & Eye & Black & Kiwi \\
\hline Plate & Plateau & Sparrow & Brain & Magenta & Plum \\
\hline Ladle & Island & Owl & Chest & Indigo & Pineapple \\
\hline Blender & Cliff & Ostrich & Knee & Grey & Watermelon \\
\hline Tray & Valley & Woodpecker & Ankle & Tan & Apple \\
\hline Colander & Beach & Cardinal & Heel & Violet & Blueberry \\
\hline Grater & Desert & Sparrow & Shoulder & Silver & Raspberry \\
\hline Instrument & Flower & Animal & Country & Precious Stone & Tree \\
\hline Piano & Lily & Lion & Germany & Ruby & Birch \\
\hline Clarinet & Rose & Horse & France & Emerald & Maple \\
\hline Guitar & Dandelion & Tiger & China & Sapphire & Palm \\
\hline Violin & Pansy & Deer & Brazil & Amethyst & Chestnut \\
\hline Harp & Orchid & Mouse & Australia & Turquoise & Fir \\
\hline Banjo & Iris & Pig & India & Quartz & Willow \\
\hline Flute & Daisy & Dog & Spain & Diamond & Evergreen \\
\hline Trumpet & Carnation & Cat & Italy & Pearl & Pine \\
\hline Drum & Tulip & Bear & Canada & Gem & Spruce \\
\hline Tube & Petunia & Cow & Russia & Topaz & Cedar \\
\hline Horn & Daffodil & Duck & Sweden & Garnet & Elm \\
\hline Cello & Lilac & Giraffe & Chile & Jade & Sycamore \\
\hline Accordion & Gardenia & Elephant & Austria & Opal & Ash \\
\hline Oboe & Azalea & Kangaroo & Iran & Aquamarine & Birch \\
\hline Saxophone & Marigold & Snake & Cuba & Garnet & Oak \\
\hline
\end{tabular}


flanking, and baseline. To provide converging evidence for hit-rate analyses, in footnotes beneath the critical comparisons we also report the discrimination measure, $P r$, and the associated bias measure, $B r^{2}$ (Feenan \& Snodgrass, 1990). All pre-planned t-tests are accompanied by scaled JZS Bayes factor to quantify support for the null or alternative hypothesis (Rouder, Speckman, Sun, Morey, $\&$ Iverson, 2009). Significant t-tests are also accompanied by Cohen's $d$ measure of effect size.

\section{Results}

In the picture-recognition condition, a repeated measures ANOVA comparing the means for baseline, flanking, and target objects $\left(F(2,86)=51.270, p<.001, \eta_{\mathrm{p}}{ }^{2}=.544\right)$ indicated a reliable difference among the three object types (Fig. 3). Memory for flanking objects (.53) was significantly worse than memory for baseline objects $\left(.69, t(43)=5.72, p<.001, d=.77\right.$, scaled $\left.\mathrm{JZS}^{3}=17,889\right)$, and memory for target objects (.84) was significantly better than baseline $(.69, t(43)=4.94, p<.001, d=.86$, scaled JZS=1,624). ${ }^{4}$ The significantly lower memory for flanking objects relative to baseline objects is the signature recognition-induced forgetting effect, replicating previous studies using this paradigm (Maxcey, 2016; Maxcey \& Bostic, 2015; Maxcey et al., 2016; Maxcey et al., 2017; Maxcey \& Woodman, 2014; Rugo et al., 2017). These results mimic the difference-of-Gaussian shape (Fig. 1) often shown in studies of recognitioninduced forgetting.

In the word-recognition condition, replicating the pattern found with pictures, a repeated measures ANOVA comparing the means for baseline, flanking, and target objects $\left(F(2,86)=14.616, p<.001, \eta_{\mathrm{p}}{ }^{2}=.255\right)$ indicated a reliable difference among the three object types (Fig. 3). Memory for flanking words (.72) was significantly worse than memory for baseline words $(.78, t(43)=2.46, p=.018$, $d=.57$, scaled JZS $=2.39)$, and target words $(.85)$ were significantly better than baseline words $(.78, t(43)=3.34$, $p=.002, d=.57$, scaled JZS $=18.13) .^{5}$ This demonstration of recognition-induced forgetting of words shows that

\footnotetext{
${ }^{2} B r$ values greater than .5 are indicative of a liberal bias while values lower than .5 indicate a conservative bias. When calculating $B r, \operatorname{Pr}$ values of 1 were changed to .99 .

${ }^{3}$ JZS Bayes factor provides a way of quantifying support for either the null or alternative hypothesis (Rouder et al., 2009). For example, here the alternative hypothesis is 17,889 times more likely to be true than the null.

${ }^{4}$ Recognition-induced forgetting for pictures replicates when using $P r$, with baseline $\operatorname{Pr}(.47)$ significantly higher than flanking $\operatorname{Pr}(.31),(t(43)=5.271$, $\mathrm{p}<.001, d=.74$, scaled JZS $=4,453$ in favor of the alternative), and conservative biases for both baseline ( $B r=.43)$ and flanking $(B r=.33)$.

${ }^{5}$ Recognition-induced forgetting of words replicates when using $P r$. Baseline $\operatorname{Pr}(.70)$ is significantly higher than flanking $\operatorname{Pr}(.65),(t(43)=2.457, p=.018$, $d=.33$, scaled $\mathrm{JZS}=2.38$ in favor of the alternative), with conservative biases for both baseline $(B r=.25)$ and flanking $(B r=.25)$.
}

retrieval is not the only task that leads to this type of within-category interference and provides proof of a general within-category interference effect that takes on the shape of a difference-of-Gaussian function.

\section{Discussion}

We first replicated previous studies showing that recognition practice for pictures results in recognition-induced forgetting. Next, we showed that the recognition practice task also leads to forgetting of words. This important ability to induce forgetting over different modalities in the same paradigm allows us to use identical tasks to directly compare memory across modalities.

\section{Experiment 2}

A critical difference among theories of forgetting is the role of executive control. Executive control is manipulated in access-based forgetting paradigms by changing the task in the second phase from recognition practice to restudy by instructing subjects to study the images for a later test, an identical task to the first phase. The logic behind this manipulation is that if forgetting of flanking memories occurs because their suppression is necessary to successfully retrieve the target memory, then eliminating a memory retrieval task will also eliminate forgetting. This role of executive control in forgetting has been argued to support a variety of opposing theories of forgetting (e.g., Anderson, 2003; Jonker et al., 2013; Kim et al., 2014). For example, evidence that access-based forgetting occurs when there is no apparent reason to use executive control to suppress memories (Kim et al., 2014) casts doubt on theories of a direct role of executive control in access-based forgetting. This critical restudy manipulation has never been implemented in the recognition-induced forgetting paradigm. Here we tested whether pictures and words behave similarly when recognition practice is replaced by restudy in the second phase.

\section{Methods}

The methods were identical to Experiment 1 with the following exceptions.

\section{Participants}

The subjects were 88 new students from The Ohio State University, randomly assigned to the picture-restudy condition (44 subjects, mean age of 19.2 years, 23 female, 21 male) 


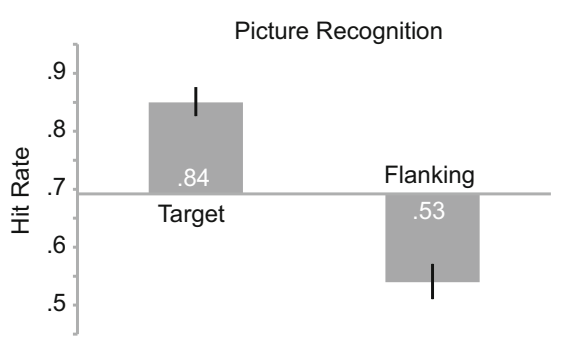

Fig. 3 Hit rate for old objects in the test phase across object type from the picture and word recognition-practice conditions. In all data figures, $\mathrm{x}-$ axis represents memory for baseline objects and error bars represent $95 \%$

or the word-restudy condition (44 subjects, mean age of 20.0 years, 24 female, 20 male).

\section{Procedure}

The practice phase was replaced with a restudy phase. In the restudy phase subjects were given the same instructions as the study phase. They were instructed to remember the items for a later memory test. The items were presented just as in the study phase, for $5 \mathrm{~s}$ interleaved by a $500-\mathrm{ms}$ fixation cross. Subjects did not respond to the stimuli in the second phase, just as they did not respond on each trial in the study phase. Although the task changed in the second phase of Experiment 2 as described above, the specific stimuli and number of trials did not change from Experiment 1.

\section{Results}

In the picture-restudy condition, a repeated measures ANOVA comparing the means for baseline, flanking, and target objects $\left(\mathrm{F}(2,86)=100.120, \mathrm{p}<.001, \eta_{\mathrm{p}}{ }^{2}=.700\right)$ indicated a reliable difference among the three object types (Fig. 4). Memory for target objects (.86) was reliably above baseline $(.60, t(43)=10.85, p<.001, d=1.66$, scaled JZS $=1.09293 \mathrm{e}+11$ ) and memory for flanking objects (.49) was significantly below baseline (.60, $t(43)=3.51, p=.001, d=.55$, scaled $\mathrm{JZS}=28) .^{6}$ Recognition-induced forgetting occurred for pictures despite the subjects' task being restudy and not recognition. This novel test of restudying pictures in the recognition-induced forgetting paradigm demonstrates that, in addition to previous evidence showing recognition leads to the forgetting of pictures, restudying pictures also results in forgetting.

\footnotetext{
${ }^{6}$ Recognition-induced forgetting following picture restudy replicates when measuring $\operatorname{Pr}$. Baseline $\operatorname{Pr}(.39)$ is significantly higher than flanking $\operatorname{Pr}$ (.29), $(t(43)=3.507, p=.001, d=.52$, scaled JZS $=27.81$ in favor of the alternative), with conservative biases for both baseline $(B r=.35)$ and flanking $(B r=.30)$.
}

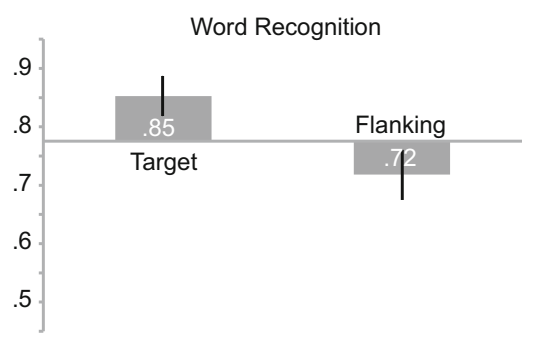

confidence intervals as described by Cousineau (2005) with Morey's correction applied (Morey 2008)

In the word-restudy condition, a repeated measures ANOVA comparing the means for baseline, flanking, and target objects $\left(F(2,86)=48.911, p<.001, \eta_{\mathrm{p}}{ }^{2}=.532\right)$ indicated a reliable difference among the three object types (Fig. 4). Memory for target words (.91) was significantly above baseline $(.72, t(43)=8.88, p<.001, d=1.41$, scaled $\mathrm{JZS}=342,977,597)$ but memory for flanking words $(.73)$ was not significantly below baseline $(.72, t(43)=0.66$, $p=.516$, scaled JZS $=4.99$ in favor of the null). ${ }^{7}$ Evidence that words were not forgotten during restudy is in contrast to forgetting of pictures, which does occur following restudy.

\section{Discussion}

Replacing recognition practice with restudy eliminated forgetting of words but not pictures. This difference between induced forgetting of pictures and words in the same task demonstrates modality-specific forgetting because here the recognition-induced forgetting effect for words was completely eliminated.

\section{Experiment 3}

Experiments 1 and 2 have a potential confound. When we are changing stimulus material, we are also changing the level of categorical organization. Specifically, the words are grouped in relation to a superordinate category cue (e.g., color), whereas the pictures are grouped by a basic-level category cue (e.g., vase). To rule out the possibility that changing the level of categorical organization, not stimulus modality, is driving these results we grouped pictures along superordinate categories (like the word stimuli in Experiments 1 and 2) in a recognition

\footnotetext{
${ }^{7}$ The absence of recognition-induced forgetting following word restudy replicates with $\operatorname{Pr}$. Baseline $\operatorname{Pr}$ (.61) is not significantly higher than flanking $P r$ (.64), $(t(43)=1.262, p=.214$, scaled JZS=2.92 in favor of the null), with conservative biases for both baseline ( $B r=.25)$ and flanking $(B r=.26)$.
} 


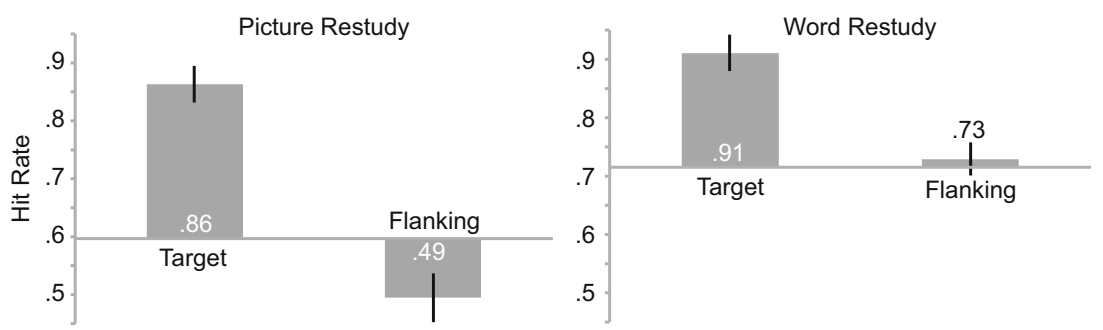

Fig. 4 Hit rate for old objects in the test phase across object type from the picture and word restudy conditions of Experiment 2

practice task. If pictures are not susceptible to forgetting when grouped at the superordinate level that words are grouped, then the difference in forgetting of pictures and words in Experiments 1 and 2 cannot be due to a difference in categorical organization.

\section{Methods}

The methods were identical to Experiment 1 with the following exceptions.

\section{Participants}

The subjects were 48 new students from The Ohio State University (mean age of 19.0 years, 22 female, 26 male).

\section{Stimuli}

The full stimulus set consisted of 18 basic level objects belonging to 12 superordinate categories (Appendix B). The stimulus set was larger to add more trials to the test phase, increasing task difficulty. Our previous studies using superordinate categories have shown very high accuracy and no forgetting (Maxcey et al., 2017). Although Experiment 3 here is different in a number of ways, we increased task difficulty to increase the likelihood of forgetting. All 18 objects were only used in any given category if that category was practiced because the practice phase requires the use of six novel

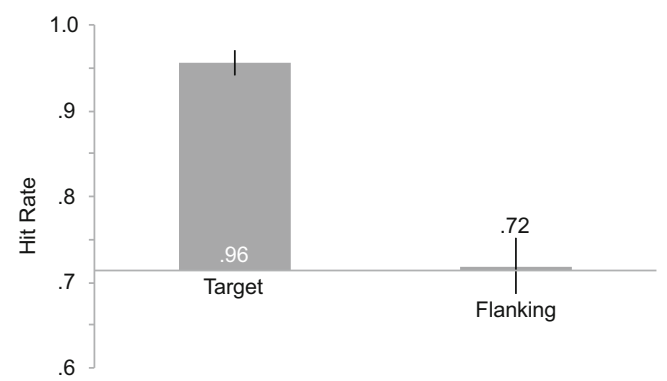

Fig. 5 Hit rate for old objects in the test phase across object type from Experiment 3 items for a 50/50 distribution in the old-new recognition judgment task (Maxcey, 2016).

\section{Procedure}

In each phase, the objects were sequentially presented below the name of the relevant superordinate category. For example, a desk was presented below the word "classroom" and a roll of toilet paper was presented below the word "bathroom."

The test phase consisted of 144 trials with 72 old items and 72 new items. The old items were all the items from the study phase and the new items were drawn from the same superordinate categories. As stated above, this change was made to increase task difficulty in order to measure forgetting based on pilot data.

\section{Results}

A repeated measures ANOVA comparing the means for baseline, flanking, and target objects $(F(2,94)=89.12$, $\mathrm{p}<.001, \eta_{\mathrm{p}}{ }^{2}=.65$ ) indicated a reliable difference among the three object types (Fig. 5). Mean hit rates for target objects (.96) was significantly better than memory for baseline objects $(.71, t(47)=11.08, p<.001, d=.2 .19$, scaled JZS=666,424,462,798 in favor of the alternative), but flanking memories $(.72)$ were not significantly different than baseline $(.71, t(47)=0.30, p=.769$, scaled $\mathrm{JZS}=6.11$ in favor of the null). ${ }^{8}$ The absence of recognition-induced forgetting here demonstrates that recognition-induced forgetting does not operate over objects grouped at the superordinate level.

\section{Discussion}

These results show that the inhibitory pulse that surrounds a target representation in visual long-term memory does not

\footnotetext{
${ }^{8}$ The absence of recognition-induced forgetting for pictures associated along superordinate categories replicates when using $\operatorname{Pr}$. Baseline $\operatorname{Pr}(.63)$ is not significantly different than flanking $\operatorname{Pr}(.64),(t(43)=0.296, p=.769$, scaled $\mathrm{JZS}=5.88$ in favor of the null), with conservative biases for both baseline $(\mathrm{Br}=.23)$ and flanking ( $\mathrm{Br}=.26)$.
} 
extend into superordinate-level category space following recognition practice. The identical recognition practice task with words grouped at this same superordinate category level did, however, lead to forgetting in Experiment 1. This dissociation between forgetting of pictures and words supports the conclusion of modality-specific forgetting.

\section{General discussion}

Here we asked whether the nature of the memoranda determines the forgetting mechanism. To this end we tested forgetting following recognition practice and restudy of both pictures and words. We found that both pictures and words were susceptible to forgetting following recognition practice. Next we found that only pictures, not words, were forgotten following restudy. Finally, we found that pictures organized at the superordinate level are not forgotten following recognition practice, even though words organized at the same categorical level are forgotten. This illustrates another key distinction between the forgetting of pictures and words. Specifically, the distance in category space that is susceptible to the inhibitory surround (see Fig. 1) differs between pictures and words.

The absence of forgetting following restudy of pictures is a critical distinction that should not have occurred according to theories of forgetting positing a direct role of executive control in access-based forgetting (Anderson, 2003; Jonker et al., 2013; Storm \& Levy, 2012). Specifically, some theories of forgetting explain the difference-of-Gaussian shape as due to executive control being recruited to suppress competing memories. These theories predict that forgetting should not occur during restudy because memory is not being accessed, so there is no need to suppress competing memories. However, it is possible that the difference in forgetting following restudy of pictures and words involves subjects engaging in recognition of the pictures without instruction to do so (as in Anderson \& Bell, 2001; Dobler \& Bäuml, 2013). The visually distinct nature of pictures may trigger an episodic recollection that does not occur with words because words have been encountered countless times. While we cannot rule out that subjects are engaging in a recognition task when instructed to restudy pictures in Experiment 2, this possibility does not pose a problem for the conclusion of modality-specific forgetting mechanisms for three main reasons. First, if the visual detail of picture stimuli led to additional processing of pictures relative to words in Experiment 2, making these pictures more readily accessed during restudy, then memory for such highly distinct materials would be better. Contrary to this prediction, memory for all three object types (i.e., baseline, target, flanking) was higher for words, not pictures. Second, Experiment 3 shows that pictures and words grouped at the same superordinate category level are differentially impacted by forgetting. Specifically, words grouped at the superordinate level show recognitioninduced forgetting (Experiment 1) but pictures do not (Experiment 3). Therefore, even if subjects are engaging in different tasks across modalities following restudy instructions in Experiment 2, memory for the two memoranda responds differently to recognition practice when grouped at the same superordinate level (Experiment 1 for words and Experiment 3 for pictures), a difference that cannot be dismissed by suggesting that subjects are engaging in a different task with pictures than words. Third, the possibility that the nature of visual stimuli, and the visual world in general, is richly detailed enough that encounters with visual objects trigger different memory mechanisms than words, is precisely the argument we make here of modality-specific forgetting. If characteristics of the visual world (e.g., color) must be removed in order to alter patterns of forgetting (Ensor, Surprenant, \& Neath, 2018), this supports the conclusion that theories of forgetting must account for a variety of stimulus materials, including and especially those encountered in daily life. That is, because removing the color from visual objects is not how we encounter objects in the real world, such a test is not a good indicator of how we forget real world visual objects.

These results promote the necessity to expand empirical examination of remembering and forgetting beyond one type of stimulus material. It is imperative that theories of forgetting derived with one stimulus material either be revised to explicitly state that they account for the forgetting of the particular memoranda tested or be empirically validated using each of the stimulus materials which they claim to explain. Indeed, deriving theories of forgetting without consideration for modality specificity, much like the early studies of memory were primarily conducted with only verbal material (Atkinson \& Shiffrin, 1968), impairs our ability to empirically determine best practices for real-world applications across modalities such as eyewitness testimony.

Acknowledgements We thank Michael Anderson for providing us with the word stimuli and providing feedback on our data. We also thank Ian Neath for his useful online models of recognition memory ${ }^{9}$ and feedback on recognition measurement. Finally, we are grateful to Jeffrey Rouder for his online scaled JZS Bayes factor calculator. ${ }^{10}$

\footnotetext{
$\overline{9}$ https://memory.psych.mun.ca/models/recognition/index.shtml

${ }^{10} \mathrm{http}: / /$ pcl.missouri.edu/bayesfactor
} 


\section{Appendix A}

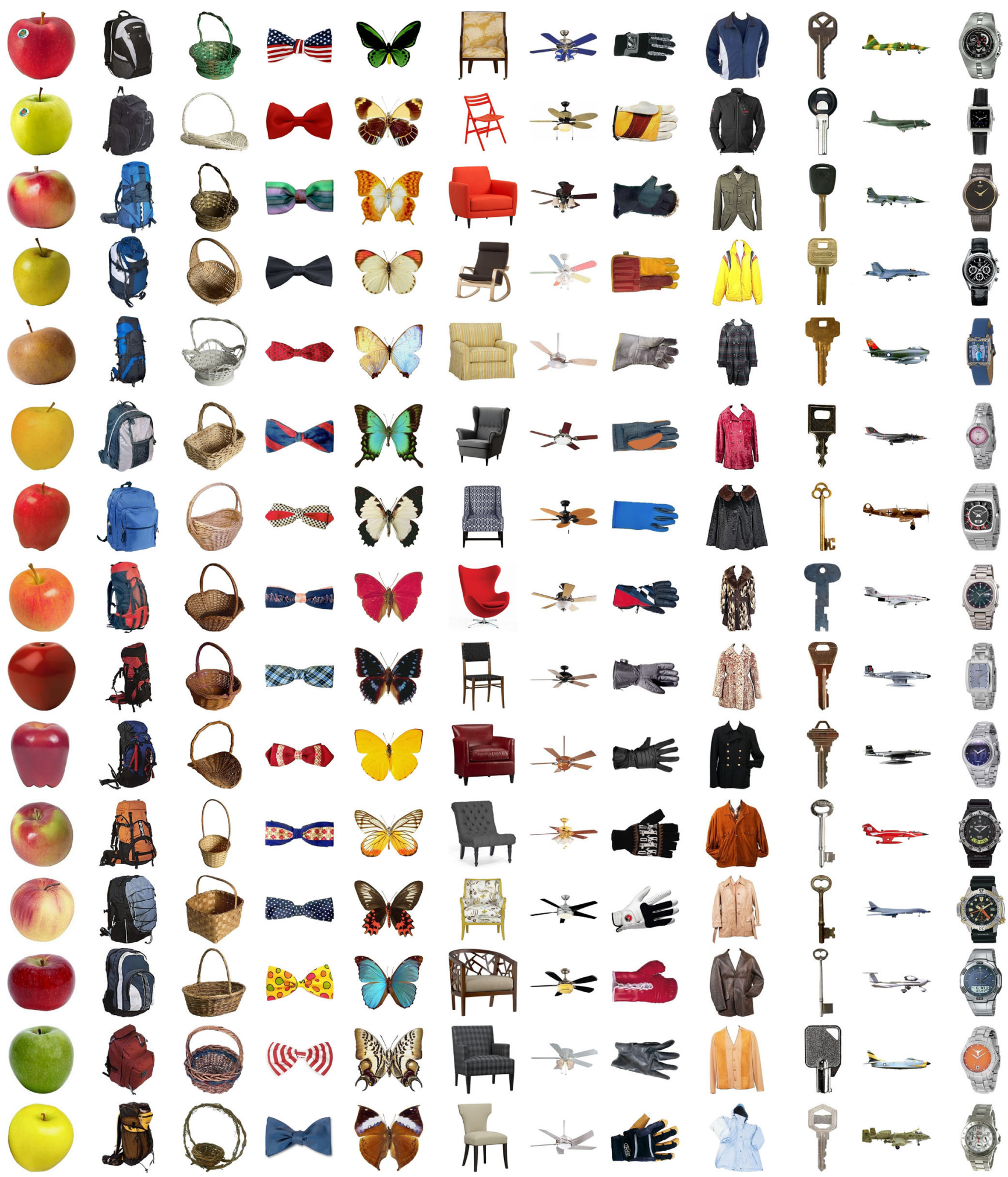

Fig. 6 Stimulus set from picture conditions in Experiments 1 and 2 


\section{Appendix B}

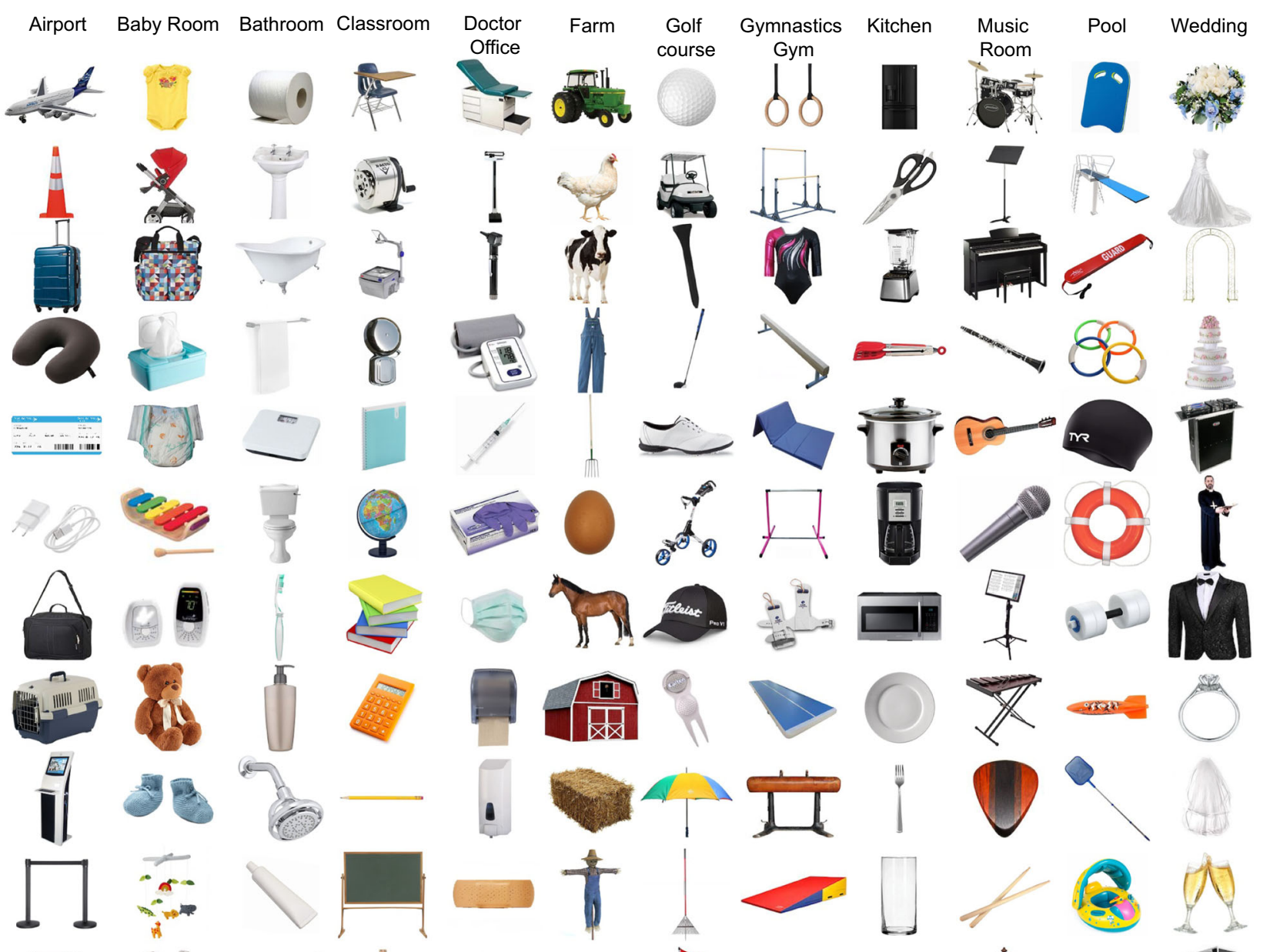

II $\mathrm{M}$

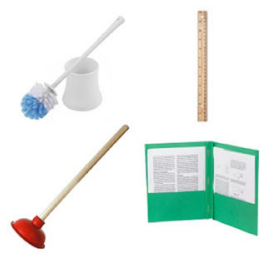

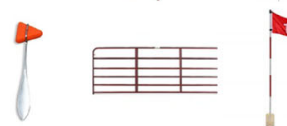

$\div 8$

$8 \frac{1}{2=}$

ra
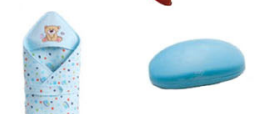

$\approx$

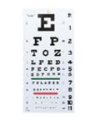

In

1)

$4 \cdot i$

.

2

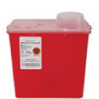
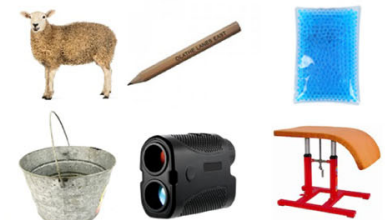

cos

\& 400

If
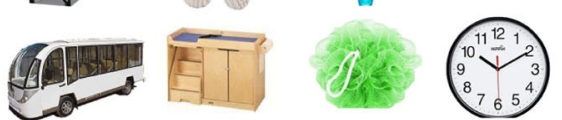

解

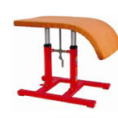

[aㅔ?
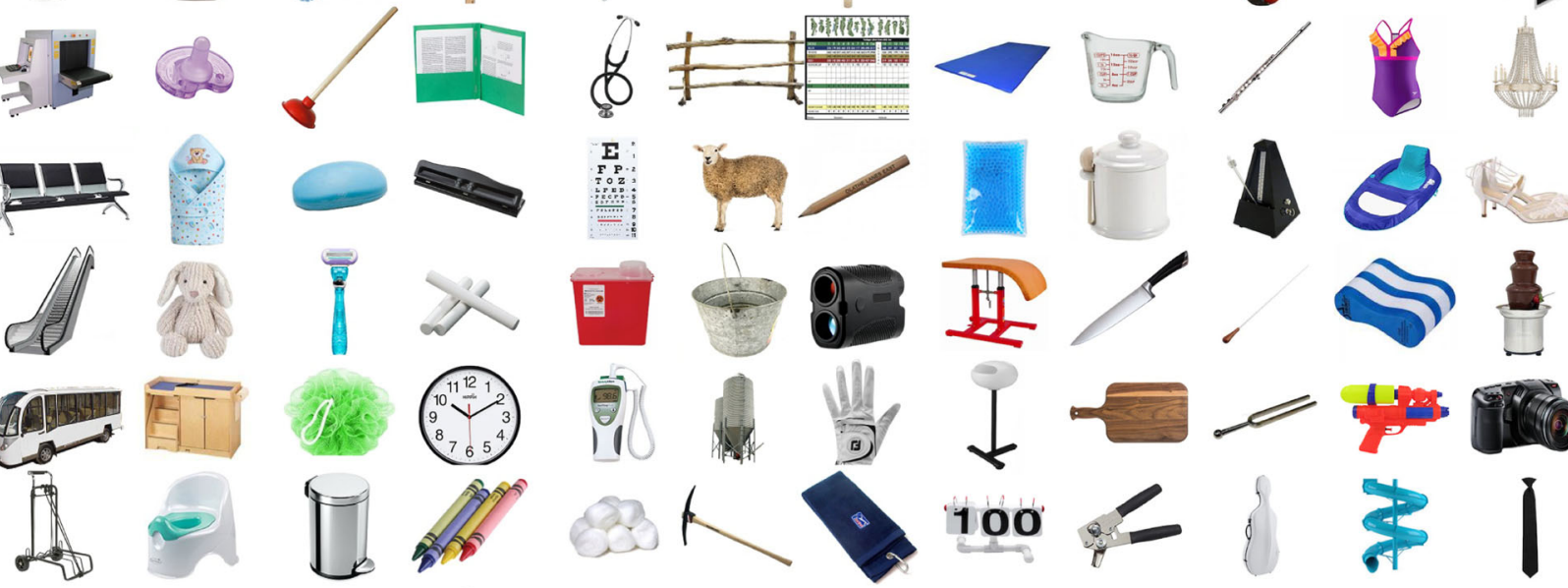

$\Delta$

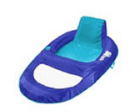

12
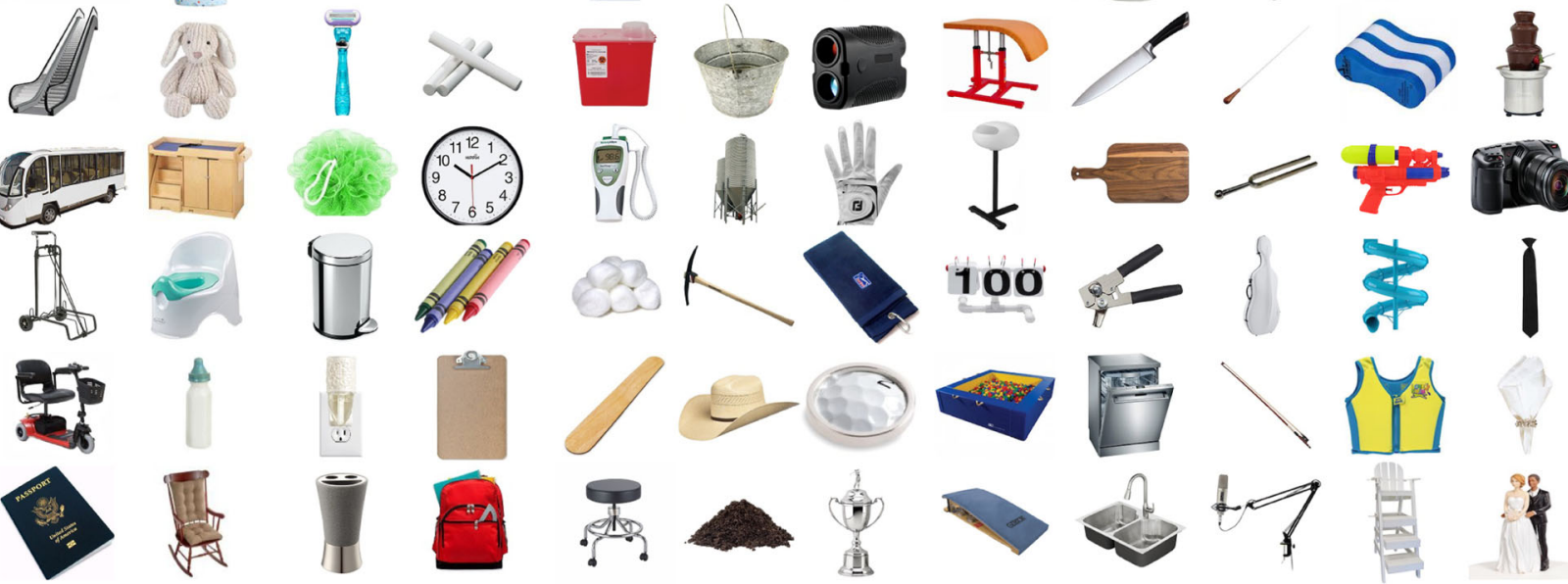

Fig. 7 Stimulus set from Experiment 3 


\section{References}

Anderson, M. C. (2003). Rethinking interference theory: Executive control and the mechanisms of forgetting. Journal of memory and language, 49, 415-445. doi:https://doi.org/10.1016/j.jml.2003.08.006

Anderson, M. C., \& Bell, T. (2001). Forgetting our facts: the role of inhibitory processes in the loss of propositional knowledge. Journal of Experimental Psychology: General, 130(3), 544.

Anderson, M. C., Bjork, R. A., \& Bjork, E. L. (1994). Remembering can cause forgetting: retrieval dynamics in long-term memory. Journal of Experimental Psychology: Learning, Memory, and Cognition, 20(5), 1063-1087. doi:https://doi.org/10.1037//0278-7393.20.5. 1063

Atkinson, R. C., \& Shiffrin, R. M. (1968). Human memory: A proposed system and its control processes. In K. W. Spence (Ed.), The Psychology of Learning and Motivation: Advances in Research and Theory Volume 2 (pp. 89-195). New York: Academic Press.

Ciranni, M. A., \& Shimamura, A. P. (1999). Retrieval-induced forgetting in episodic memory. Journal of Experimental Psychology: Learning, Memory, and Cognition, 25(6), 1403-1414. doi:https:// doi.org/10.1037/0278-7393.25.6.1403

Cousineau, D. (2005). Confidence intervals in within-subject designs: A simpler solution to Loftus and Masson's method. Tutorial in Quantitative Methods for Psychology, 1, 42-45.

Cunningham, C. A., Yassa, M. A., \& Egeth, H. E. (2015). Massive memory revisited: Limitations on storage capacity for object details in visual long-term memory. Learning \& Memory, 22(11), 563-566.

Detre, G. J., Natarajan, A., Gershman, S. J., \& Norman, K. A. (2013). Moderate levels of activation lead to forgetting in the think/no-think paradigm. Neuropsychologia, 51(12), 2371-2388. doi:https://doi. org/10.1016/j.neuropsychologia.2013.02.017

Dobler, I. M., \& Bäuml, K.-H. T. (2013). Retrieval-induced forgetting: dynamic effects between retrieval and restudy trials when practice is mixed. Memory \& Cognition, 41(4), 547-557. doi:https://doi.org/10. 3758/s13421-012-0282-5

Durso, F. T., \& O'Sullivan, C. S. (1983). Naming and remembering proper and common nouns and pictures. Journal of Experimental Psychology: Learning, Memory, and Cognition, 9(3), 497-510. doi:https://doi.org/10.1037/0278-7393.9.3.497

Ensor, T. M., Surprenant, A. M., \& Neath, I. (2018). Increasing word distinctiveness eliminates the picture superiority effect in recognition: Evidence for the physical-distinctiveness account. Memory \& Cognition, 1-12.

Faul, F., Erdfelder, E., Lang, A.-G., \& Buchner, A. (2007). G*Power 3: A flexible statistical power analysis for the social, behavioral, and biomedical sciences. Behavioral Research Methods, 39, 175-191.

Feenan, K., \& Snodgrass, J. G. (1990). The effect of context on discrimination and bias in recognition memory for pictures and words. Memory \& Cognition, 18(5), 515-527.

Gehring, R. E., Toglia, M. P., \& Kimble, G. A. (1976). Recognition memory for words and pictures at short and long retention intervals. Memory \& Cognition, 4(3), 256-260. doi:https://doi.org/10.3758/ BF03213172

Gómez-Ariza, C. J., Fernandez, A., \& Bajo, M. T. (2012). Incidental retrieval-induced forgetting of location information. Psychonomic bulletin \& review, 19(3), 483-489.

Hockley, W. E. (2008). The picture superiority effect in associative recognition. Memory \& Cognition, 36(7), 1351-1359. doi: https://doi. org/10.3758/MC.36.7.1351

Jonker, T. R., Seli, P., \& MacLeod, C. M. (2013). Putting retrieval-induced forgetting in context: an inhibition-free, context-based account. Psychological Review, 120(4), 852-872. doi:https://doi.org/ 10.1037/a0034246
Juola, J. F., Taylor, G. A., \& Young, M. E. (1974). Stimulus encoding and decision processes in recognition memory. Journal of Experimental Psychology, 102(6), 1108. doi:https://doi.org/10.1037/h0036370

Kelley, M. R., Neath, I., \& Surprenant, A. M. (2015). Serial position functions in general knowledge. Journal of Experimental Psychology: Learning, Memory, and Cognition, 41(6), 1715.

Kim, G., Lewis-Peacock, J. A., Norman, K. A., \& Turk-Browne, N. B. (2014). Pruning of memories by context-based prediction error. Proceedings of the National Academy of Sciences, 111(24), 89979002.

Konkle, T., Brady, T. F., Alvarez, G. A., \& Oliva, A. (2010a). Conceptual distinctiveness supports detailed visual long-term memory for realworld objects. Journal of Experimental Psychology: General, 139(3), 558.

Konkle, T., Brady, T. F., Alvarez, G. A., \& Oliva, A. (2010b). Scene memory is more detailed than you think: the role of categories in visual long-term memory. Psychological science, 21(11), 15511556.

Koutstaal, W., \& Schacter, D. L. (1997). Gist-based false recognition of pictures in older and younger adults. Journal of memory and language, 37(4), 555-583.

Lewis-Peacock, J. A., \& Norman, K. A. (2014). Competition between items in working memory leads to forgetting. Nature Communications, 5, 5768. doi:https://doi.org/10.1038/ ncomms6768

Madigan, S. (1974). Representational storage in picture memory. Bulletin of the Psychonomic Society, 4(6), 567-568. doi:https://doi.org/10. 3758/BF03334293

Maxcey, A. M. (2016). Recognition-induced forgetting is not due to category-based set size. Attention, Perception, \& Psychophysics, 78(1), 187-197. doi:https://doi.org/10.3758/s13414-015-1007-1

Maxcey, A. M., \& Bostic, J. (2015). Activating learned exemplars in children impairs memory for related exemplars in visual long-term memory. Visual Cognition, 23(5), 643-558. doi:https://doi.org/10. 1080/13506285.2015.1064052

Maxcey, A. M., Bostic, J., \& Maldonado, T. (2016). Recognition practice results in a generalizable skill in older adults: decreased intrusion errors to novel objects belonging to practiced categories. Applied cognitive psychology. doi:https://doi.org/10.1002/acp.3236

Maxcey, A. M., Glenn, H., \& Stansberry, E. (2017). Recognition-induced forgetting does not occur for temporally grouped objects unless they are semantically related. Psychonomic bulletin \& review. doi:https:// doi.org/10.3758/s13423-017-1302-z

Maxcey, A. M., \& Woodman, G. F. (2014). Forgetting induced by recognition of visual images. Visual Cognition, 22(6), 789-808.

Morey, R. D. (2008). Confidence intervals from normalized data: A correction to Cousineau (2005). Tutorial in Quantitative Methods for Psychology, 4(2), 61-64.

Murayama, K., Miyatsu, T., Buchli, D., \& Storm, B. C. (2014). Forgetting as a consequence of retrieval: A meta-analytic review of retrievalinduced forgetting. Psychological bulletin, 140(5), 1383-1409. doi: https://doi.org/10.1037/a0037505

Nelson, D. L., Reed, V. S., \& McEvoy, C. L. (1977). Learning to order pictures and words: A model of sensory and semantic encoding. Journal of Experimental Psychology: human learning and memory, 3(5), 485. doi:https://doi.org/10.1037/0278-7393.3.5.485

Nelson, D. L., Reed, V. S., \& Walling, J. R. (1976). Pictorial superiority effect. Journal of Experimental Psychology: Human Learning and Memory, 2(5), 523. doi:https://doi.org/10.1037/0278-7393.2.5.523

Norman, K. A., Newman, E. L., \& Detre, G. (2007). A neural network model of retrieval-induced forgetting. Psychological Review, 114(4), 887.

Paivio, A., \& Csapo, K. (1973). Picture superiority in free recall: Imagery or dual coding? Cognitive Psychology, 5(2), 176-206. doi:https:// doi.org/10.1016/0010-0285(73)90032-7 
Paivio, A., Rogers, T. B., \& Smythe, P. C. (1968). Why are pictures easier to recall than words? Psychonomic Science, 11(4), 137-138. doi: https://doi.org/10.3758/BF03331011

Raaijmakers, J. G., \& Jakab, E. (2013a). Is forgetting caused by inhibition? Current directions in psychological science, 22(3), 205-209.

Raaijmakers, J. G., \& Jakab, E. (2013b). Rethinking inhibition theory: On the problematic status of the inhibition theory for forgetting. Journal of memory and language, 68(2), 98-122.

Rouder, J. N., Speckman, P. L., Sun, D., Morey, R. D., \& Iverson, G. (2009). Bayesian t-tests for accepting and rejecting the null hypothesis. Psychonomic bulletin \& review, 16, 225-237. doi:https://doi. org/10.3758/PBR.16.2.225

Rugo, K. F., Tamler, K. N., Woodman, G. F., \& Maxcey, A. M. (2017). Recognition-induced forgetting of faces in visual long-term memory. Attention, Perception, \& Psychophysics, 79, 1878-1885. doi: https://doi.org/10.3758/s13414-017-1419-1

Schlichting, M. L., \& Preston, A. R. (2015). Memory integration: neural mechanisms and implications for behavior. Current opinion in behavioral sciences, 1, 1-8.

Schneider, W., Eschman, A., \& Zuccolotto, A. (2012). E-Prime Reference Guide. Pittsburgh: Psychology Software Tools, Inc.

Shaw, J., Bjork, R., \& Handal, A. (1995). Retrieval-induced forgetting in an eyewitness-memory paradigm. Psychonomic bulletin \& review, 2(2), 249-253. doi:https://doi.org/10.3758/bf03210965
Snodgrass, J. G., \& Burns, P. M. (1978). The effect of repeated tests on recognition memory for pictures and words. Bulletin of the Psychonomic Society, 11(4), 263-266. doi:https://doi.org/10.3758/ bf03336826

Snodgrass, J. G., Volvovitz, R., \& Walfish, E. R. (1972). Recognition memory for words, pictures, and words+ pictures. Psychonomic Science, 27(6), 345-347. doi:https://doi.org/10.3758/BF03328986

Snodgrass, J. G., Wasser, B., Finkelstein, M., \& Goldberg, L. B. (1974). On the fate of visual and verbal memory codes for pictures and words: Evidence for a dual coding mechanism in recognition memory. Journal of verbal learning and verbal behavior, 13(1), 27-37. doi:https://doi.org/10.1016/S0022-5371(74)80027-7

Storm, B. C., \& Levy, B. J. (2012). A progress report on the inhibitory account of retrieval-induced forgetting. Memory and Cognition, 40(6), 827-843. doi:https://doi.org/10.3758/s13421-012-0211-7

Tempel, T., Aslan, A., \& Frings, C. (2016). Competition dependence of retrieval-induced forgetting in motor memory. Memory \& Cognition, 44(4), 671-680.

Underwood, B. J. (1957). Interference and forgetting. Psychological Review, 64, 49-60.

Publisher's note Springer Nature remains neutral with regard to jurisdictional claims in published maps and institutional affiliations. 